\title{
Removal of catheter fragments from pulmonary artery using a snare
}

\author{
Eliot Schechter and Alfred F. Parisi ${ }^{1}$ \\ From the Cardiology Service, Department of Medicine, Wilford Hall USAF Medical Centre, \\ Lackland Air Force Base, Texas, U.S.A.
}

In two patients, indwelling polyethylene catheters embolized to the pulmonary artery after being dislodged into the venous circulation during resuscitative efforts. Both were successfully extracted using a snare catheter. The use of radio-opaque material for indwelling catheters provides a valuable aid in the event of one being dislodged. The use of the snare catheter may obviate the need for thoracotomy in these cases.

Widespread use of venous catheters frequently leads to complications. Loss of a catheter fragment into the central circulation may result in perforation, embolization, or sepsis (Harken and Zoll, 1946). Usually, thoracotomy is necessary for removal (Lillehei, Bonnabeau, and Grossling, 1965; Steiner et al., 1965), but recently a ureteral basket was used to retrieve a catheter fragment from the distal aorta (Lassers and Pickering, 1967) and wire snares to remove catheters from the right atrium (Massumi and Ross, 1967) and inferior vena cava (Ramo et al., I968). Successful removal of catheter fragments from more central sites has not been reported. This communication illustrates that the snare technique is also feasible for removing catheters from the pulmonary artery.

\section{Case reports}

Case 1 A 37-year-old man suffered a myocardial infarction. During resuscitation, a radio-opaque polyethylene catheter in the jugular vein escaped into the venous circulation. Chest $x$-ray showed it in the left main pulmonary artery. When referred three months later he had no symptoms referable to the catheter. A snare catheter was introduced via the right saphenous vein and passed into the pulmonary artery adjacent to the polyethylene fragment. The snare was opened and, after several attempts, slipped over the tip (Fig. I). The snare was tightened and the entire unit withdrawn without difficulty. A long organized thrombus was hanging from the tip of the polyethylene catheter.

Received 6 September 1971.

${ }^{1}$ Present address: Division of Cardiology, VA Hospital, 3900 Loch Raven Blvd, Baltimore, Maryland 21218 , U.S.A.
Case 2 A 21-year-old man sustained a 30-06 bullet wound in the jaw, larynx, and right chest. At the time of surgical repair a radio-opaque catheter was inserted into the left subclavian vein. This broke and subsequently migrated to the

FIG. I Right anterior oblique view of catheter fragment in pulmonary artery with snare in position. 
junction of the main and left pulmonary arteries. After operation the patient developed fever and cellulitis. Ampicillin therapy was started, but he remained febrile. Serratia marcescens was cultured from his blood. Because of bacteraemia and persistent fever, it was decided that the entrapped intravascular catheter should be removed. It was extracted using a snare catheter and the technique described below.

\section{Technique and comments}

The snares were fashioned from a No. 8 Teflon catheter and $0.025^{\prime \prime}$ spring guide (Fig. 2) ${ }^{1}$. The wire ends were led out through a $Y$ connector which allowed continuous catheter flushing to prevent clotting within the Teflon catheter.

The catheter was passed from a right saphenous vein cutdown. Difficulty crossing the tricuspid valve and in selectively entering the right or left pulmonary artery because of the straight configuration of the catheter tip was avoided by using a bent Seldinger wire.

After the catheter was positioned in the pulmonary artery the guide wire was removed and the snare loop was inserted.

Once the polyethylene catheter was entrapped in the snare a haemostat was used to fix the wires in position and the entire unit was withdrawn. No difficulty was experienced during passage through the cardiac chambers, inferior vena cava, and femoral or saphenous veins.

The successful removal of catheter fragments from the pulmonary artery in these two cases further emphasizes the importance of using radio-opaque tubing and extends the role of the catheter as an instrument of therapy as well as diagnosis.

\section{References}

Harken, D. E., and Zoll, P. M. (1946). Foreign bodies in and in relation to the thoracic blood vessels and heart. American Heart fournal, 32, I.

Lassers, B. W., and Pickering, D. (1967). Removal of an iatrogenic foreign body from the aorta by means of a ureteric stone catcher. American Heart fournal, 73, 375 .

Lillehei, C. W., Bonnabeau, R. C., Jr., and Grossling, S. (1965). Removal of iatrogenic foreign bodies within cardiac chambers and great vessels. Circulation, 32, 782.

1 Cook, Inc CRS-I.

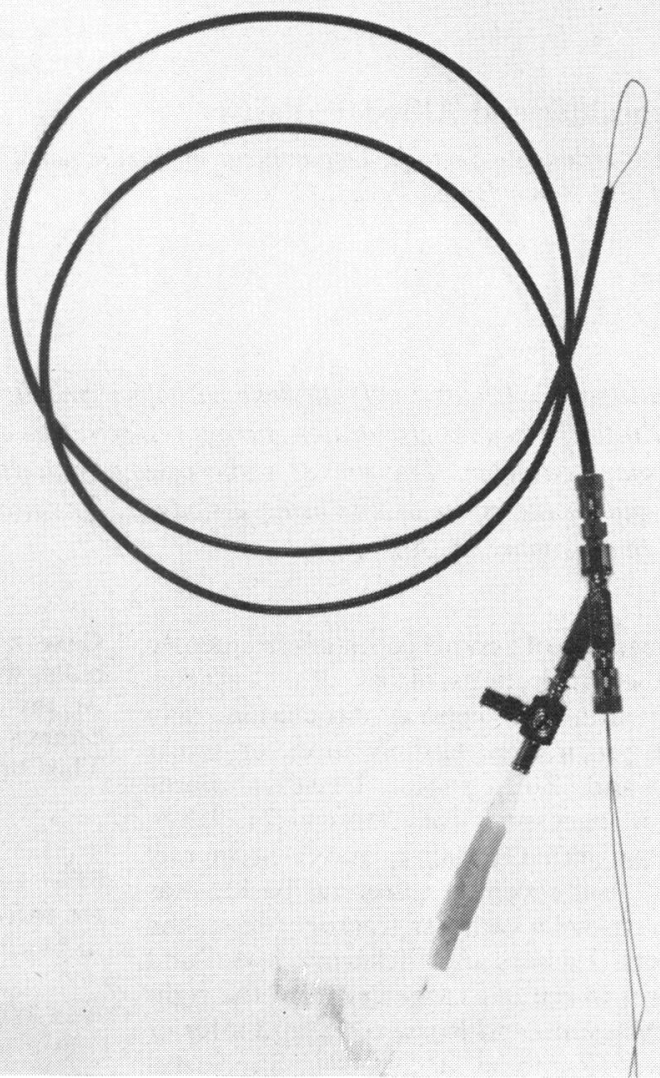

FIG. 2 The snare catheter.

Massumi, R. A., and Ross, A. M. (1967). Atraumatic, nonsurgical technic for removal of broken catheters from cardiac cavities. New England fournal of Medicine, 277, 195

Ramo, B. W., Peter, R. H., Kong, Y., and Morris, J. J., Jr. (1968). Migration of a severed transvenous pacing catheter and its successful removal. American fournal of Cardiology, 22, 880.

Steiner, M. L., Barley, T. D., Byers, F. M., and Krovetz, L. J. (1965). Polyethylene catheter in the heart. Report of a case with successful removal. fournal of the American Medical Association, 193, I054.

Requests for reprints to Lt. Colonel Eliot Schechter, Cardiology Service, Wilford Hall USAF Medical Center, Lackland Air Force Base, Texas 78236, U.S.A. 